\title{
The European Parliament as a Conditional Agenda Setter: What Are the Conditions? A Critique of Tsebelis (1994)

\author{
PETER MOSER University of St. Gallen
}

\begin{abstract}
7 sebelis (1994) argues in the American Political Science Review that the European Parliament has important power due to its right as a conditional agenda setter. I claim that Tsebelis' argument is based either on an incomplete analysis or on inaccurately specified decision rules. An accurate modeling of the cooperation procedure as stated in Article $189 \mathrm{c}$ of the Treaty of the European Community and as applied in practice changes the results considerably. Based on such a model, I provide an explanation of why the European Parliament sometimes can make successful amendments.
\end{abstract}

$\mathbf{I}$ $\mathrm{n}$ an influential paper on the cooperation procedure in the European Union (EU) that focuses, among others, on the legislative decision-making rule with which the internal market program was implemented, George Tsebelis (1994) argues that the European Parliament (EP) has an important effect on EU decisions due to its power as a conditional agenda setter. He claims that the EP can place items on the legislative agenda which would not otherwise be considered and that such amendments can sometimes result in more integration than otherwise would be chosen. Tsebelis predicts that, within the cooperation procedure, the influence of the EP is likely to increase in the future due to the curvilinear property, according to which the agenda-setting power of the EP increases if the status quo approaches the Pareto set of the Council of Ministers; that power reaches a maximum at some point and declines if the status quo moves closer to the EP's ideal position. Most important, Tsebelis argues that, in contrast to previous research, his model is capable of explaining the observation that the Commission of the European Union often accepts amendments proposed by the EP.

I would like to raise three points. First, I argue that the decision rules modeled by Tsebelis do not accurately reflect the cooperation procedure as stated in Article $189 \mathrm{c}$ of the Treaty of the European Community and as applied in practice. Second, a complete and accurate modeling of the cooperation procedure changes Tsebelis' results substantially. Third, I provide an explanation consistent with these decision rules to show why the EP sometimes can successfully amend the common position chosen by the Council. Such an explanation, however, requires a careful analysis of whether restrictions that the European Parliament faces have changed during a particular decision process, such that the EP can take advantage by proposing an amendment.

\section{TSEBELIS' MODEL}

In accordance with Tsebelis, I assume that the Council is composed of seven members with Euclidian preferences and that the qualified majority rule requires five votes.

Peter Moser is Assistant Professor of Economics University of St. Gallen, CH-9000 St. Gallen, Switzerland.

The author is grateful to Claudia Hubschmid, Bernard Steunenberg, Robert Straw, and the anonymous referees for valuable comments.
To simplify the exposition, I reduce Tsebelis' twodimensional model to a choice along one dimension (e.g., the degree of market integration). This simpler model allows me to represent his most important claims regarding the influence of the EP and the curvilinear property. ${ }^{1}$ Figure 1 depicts the ideal preference points of the seven Council members ( 1 to 7$)$, the status quo $(S Q)$, the ideal point of the EP, and two different ideal points of the Commission $\left(C_{1}, C_{2}\right)$. The preference distribution (with $C_{1}$ ) reflects the standard argument also followed by Tsebelis that the Commission and the EP prefer more integration than do the members of the Council. Furthermore, I assume that all players have complete and perfect information and that none of the players prefers its decision to be overturned, which rules out decisions to be reversed by other players.

The procedure in the Tsebelis model is the following.

1. "The Council can unanimously adopt any proposal inside the area indicated by the unanimity [win] set of the status quo, or U(SQ)" (p. 132, emphasis added). In Figure 1, this set includes all points between the status quo and the point which keeps the least integrationist member (1) indifferent to the status quo. To get the smallest possible effect of the EP, Tsebelis assumes that the Council selects the point inside $U(S Q)$ most preferred by the EP. In Figure 1, this is point $z$. Notice that if the status quo is farther to the left, $U(S Q)$ increases. In contrast, if the status quo is inside the Pareto set of the Council-the interval between 1 and $7-U(S Q)$ is empty.

2. In the second stage of Tsebelis' model, the EP can make a proposal that is approved if preferred to $z$ by the Commission and by a qualified majority in the Council. The qualified majority win set of $z, Q(z)$, represents the latter constraint, depicting the set of points preferred to $z$ by the decisive Council member (3). If the Commission's ideal point is at $C_{1}$, then the binding constraint is $Q(z)$, such that the EP can select $x$, which becomes the new status quo.

One major result of this decision structure is the curvilinear property of the relation between the location

\footnotetext{
1 I agree with Tsebelis about the fundamental differences between one- and two-dimensional models (see his footnote 5), but the curvilinear property and the influence of the EP can be illustrated by a one-dimensional representation. The only effect that thereby disappears is the possibility of selecting among different coalitions inside the Council (see Figure 4 in Tsebelis). It is left to the judgment of the reader as to which representation makes the argument more comprehensible.
} 


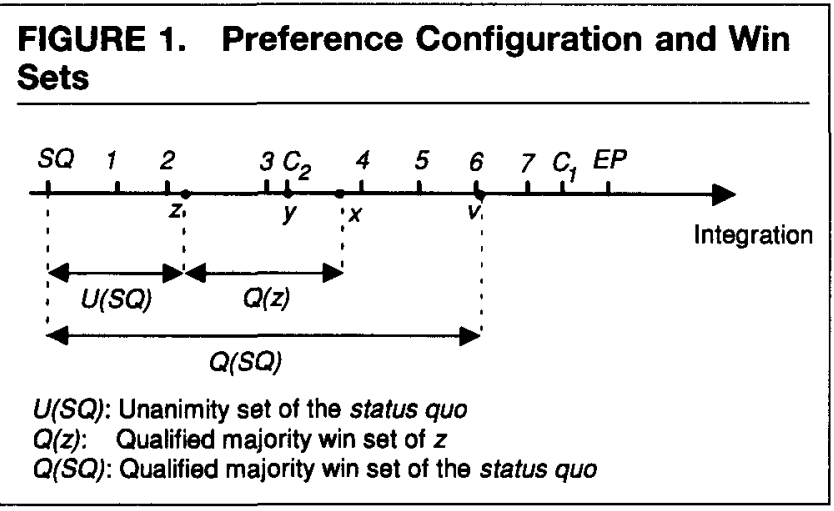

of the status quo and the agenda power of the EP. Figure 2 shows the equilibrium outcome as a function of the location of the status quo for the same preference configuration as in Figure 1. The bold line $(A B C D E)$ represents the outcome with Tsebelis' procedure. The status quo cannot be changed if $S Q$ is at or to the right of 3 (line $D E$ ). If $1 \leq S Q<3$, no unanimous change is possible, and Tsebelis argues that "consequently, the status quo can be modified only through a parliamentary proposal" (p. 133, emphasis added). Hence, the EP can choose its most preferred point inside the qualified majority win set of $S Q, Q(S Q)$, and thereby realize an outcome on the line $C D$. Situations analogous to Figure 1 occur if $S Q$ is between 1 and $I . I$ is the point that makes Council member 1 indifferent to the policy position at 3 . Finally, if $S Q<I$, the Council chooses $z$ unanimously at the maximum of $U(S Q)$. In this case, the common position $(z)$ is to the right of the ideal point of member 3 , who is decisive under the qualified majority rule. Therefore, $Q(z)$ is empty, and the EP cannot change the Council's decision.

\section{FIGURE 2. Equilibrium Outcome and the Location of the Status Quo}

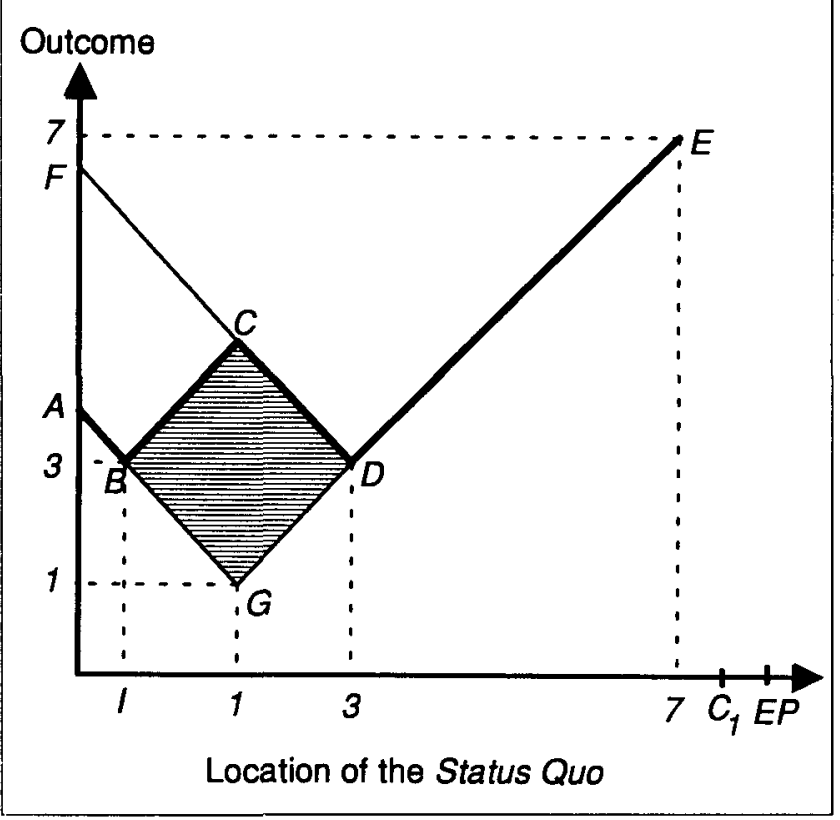

The line $A G E$ reflects the outcome of the first stage in Tsebelis' procedure: The Council acts unanimously and always chooses the highest degree of integration inside $U(S Q)$. The shaded area represents the influence of the EP, according to Tsebelis' curvilinear property: If the status quo is far outside the Pareto set, the EP has no effect. If the status quo approaches the Pareto set, the influence of the EP increases, reaching its maximum if $S Q=1$, and then declines again. This result occurs because Tsebelis supposes the following two-stage procedure: First, the Council decides unanimously without any agenda rights by the EP or the Commission. Second, the EP can make a proposal which the Council considers under the qualified majority rule. Notice that this result differs from the usual agenda-setting effects, as analyzed by Romer and Rosenthal (1978). Their model has only one stage, as is the case if the EP or the Commission can make a proposal that must be approved by a qualified majority in the Council. Thereby, the agenda setter can choose his or her most preferred policy inside the qualified majority win set of $S Q, Q(S Q)$ (policy $v$ in Figure 1). The line FDE in Figure 2 depicts the equilibrium outcome with this rule: The farther to the left the status quo is from the position of the final decision maker (here, the decisive member in the Council), the greater is the influence of the agenda setter.

In the preceding discussion, the EP and the Commission have similar preferences. To ascribe conditional agenda power to the EP, however, as Tsebelis does, it is necessary to show that the agenda-setting right of the EP is stronger than that of the Commission. Hence, a conflict of interest between these two players has to be considered. Conflicting interests exist if the two players prefer different feasible policies, both of which are supported by the Council. Tsebelis analyzes a conflict in his Figure 6 for a two-dimensional choice. His argument can again be represented for a one-dimensional choice. If the ideal point of the Commission is at $C_{2}$ in Figure 1, such that the Commission still prefers $x$ to $z$ and, as Tsebelis assumes, "the Commission can only accept or reject the EP's proposal" (p. 138), the Commission will accept $x$.

All these results depend crucially on the assumption that the Commission cannot or does not make the first proposal in the cooperation procedure, but this is an inaccurate or incomplete description of the procedure. It is inaccurate if Tsebelis' analysis is focused on the whole cooperation procedure, which he claims in his introduction: "I examine the logic and the outcomes of decision making among three institutional actors generated by the cooperation procedure" (p. 128, emphasis added). It is inaccurate in this case because the Commission always makes the first proposal, as I will discuss in the next section. If his analysis is limited to the second reading (see his remark on p. 131), then it is incomplete because he does not consider that the result of the second reading influences the strategic choices of the players in the first reading. Rather, his analysis is implicitly based on an asymmetric assumption: While the EP acts strategically in the second reading, the Commission does not use its agenda rights effectively in the first stage. In either interpretation, Tsebelis does not provide a con- 
vincing model of the cooperation procedure. In the following section, I model the agenda rights according to the treaty, incorporating both stages of the cooperation procedure, and present results fundamentally different from Tsebelis.

\section{THE COOPERATION PROCEDURE RECONSIDERED}

The cooperation procedure comprises five stages. (1) The Commission submits a proposal $(y)$ to the Council. (2) After consulting the EP (first reading), the Council determines in its first reading the common position: It can approve $y$ by a qualified majority or modify the Commission's proposal unanimously. (3) The EP can accept, modify, or reject the common position in its second reading. (4a) If the EP accepts the common position, the Council can adopt the common position by qualified majority rule in its second reading; otherwise the status quo prevails. (4b) If the EP rejects the common position, the Council is required to approve the common position unanimously; otherwise, the status quo prevails. (4c) If the EP amends the common position, the Commission decides whether to approve the amendment. (5a) If the Commission approves the amendment of the EP, the Council can accept the amended proposal by qualified majority or must pass it unanimously if modified. (5b) If the Commission rejects the amendment of the EP, the Council can approve the unamended common position by qualified majority rule or accept the proposal of the EP by unanimity.

This decision process remains undisputed, but Tsebelis claims that, in practice, the decision makers deviate from these rules in important aspects. First, he asserts that "all three institutional actors [Commission, Council, $\mathrm{EP}]$ can in fact place items on the legislative agenda" ( $\mathrm{p}$. 131, emphasis added). Thereby, Tsebelis claims that the EP has unrestricted proposal power. This stands in contrast with the legal literature, which argues that the Commission has substantial agenda control. Although the Commission agreed in 1982 to take up any parliamentary proposal to which it does not have any major objections (see Jacobs and Corbett 1990, 181), and although a majority of the EP members can request the Commission to submit a proposal since the Maastricht treaty (Article 138b), the Commission is free to decide when to make the proposal and what to include in it (see von der Groeben et al. 1991, 4307, and Lenz and Borchardt 1994, 1018 and 1059). Some legal scholars (Kapteyn and Verloren van Themaat 1989, 252) even argue that such requests are nonbinding. In any case, the Commission does have broad agenda control and is not bound by the suggestions of the EP.

Second, Tsebelis' model implies that the Council unanimously chooses a proposal on its own in the first stage. Such an interpretation underestimates the influence of the Commission, which always makes the proposal (independent of whether the issue was suggested by the EP or by the Council); the Council can modify the proposal only unanimously but approve it by qualified majority rule.

My interpretation of the cooperation procedure leads to three results that differ substantially from Tsebelis' conclusions.

\section{Result 1}

Given the preference configuration in Figure 1, actual policy shifts more toward integration than Tsebelis' model predicts. Referring to Figure $1, x$ is the maximum integration that can be achieved according to Tsebelis' model. Due to the Commission's agenda rights in the first stage, however, the Commission can choose its most preferred policy in the qualified majority win set of the status quo, $Q(S Q)$, that is also in the Pareto set (otherwise, the Council can modify the proposal). For example, a Commission with an ideal point at $C_{1}$ chooses $v$, and the Council members cannot reverse policy to $z$. This would require consent. Members 6 and 7, however, would veto any move to the left of $v$. Furthermore, $v$ is approved by a qualified majority because the decisive member 3 is better off with policy $v$ than with the status quo. Referring to Figure 2, the equilibrium outcome is depicted by the line $F D E$, the outcome predicted by the Romer-Rosenthal model. Notice, first, that for $S Q<I$ the policy shifts more toward integration than in Tsebelis' model and, second, that the curvilinear property vanishes: The farther away the status quo from the Pareto set, the closer the realized policy is to the agenda setter's most preferred policy. ${ }^{2}$

\section{Result 2}

If there is no conflict between the Commission and the EP (because both prefer more integration than the decisive member in the Council), and if the positions of the players do not change during the decision process, then the EP never has the opportunity to change the outcome. This is the standard preference configuration used by Tsebelis to analyze the effect of the EP. In this situation, however, the EP never makes an amendment but remains inactive, because the Commission has already made the optimal proposal ( $v$ in Figure 1 ) in the first stage. The difference between Tsebelis' model and mine is most obvious if the Commission and the EP have conflicting interests.

\section{Result 3}

If the Commission and the EP have conflicting interests, the EP's right to suggest amendments has no effect when both players prefer a change in the same direction and when the EP's optimal policy is farther away from the status quo than that of the Commission.

Suppose that the ideal point of the Commission is at $C_{2}$ in Figure 1. In this case, Tsebelis' model implies that the EP can propose $x$ successfully. Since he implicitly assumes that the Commission does not use its agenda rights effectively, the Council would unanimously choose $z$. Given $z$, the EP would propose $x$, which the Commission prefers to $z$. Yet, if the Commission behaves as strategically as the EP, the Commission would propose

\footnotetext{
${ }^{2}$ This point has been independently developed by Crombez (1996).
} 
in the first stage its most preferred policy $(y)$, which the Council would adopt as common position by a qualified majority. The EP prefers more integration, but such a policy change would not be supported by the Commission and would fail to receive the required unanimous support in the Council. Hence, the Commission's optimal policy $(y)$ is realized, and the EP has no effect on the decision. Only if the EP's ideal point is closer to the status quo than that of the Commission and that of the decisive Council member can the EP force the Commission to propose a smaller policy change than it would do otherwise (see Steunenberg 1994). In this respect, the $\mathrm{EP}$ is a conditional veto player. Since the veto of the EP can be outvoted by a unanimous vote of the Council in the cooperation procedure, the EP can at best force the Commission to choose a point inside the unanimity win set, $U(S Q) .^{3}$

\section{Summary}

A complete and accurate modeling of the cooperation procedure changes Tsebelis' results substantially and reestablishes the traditional claim that the EP is weak. In contrast to his results, my argument implies that the Commission, not the EP, is the decisive agenda setter. The power of the Commission does not correspond to the curvilinear property. Rather, its power increases the farther away the status quo is from the Pareto set. This implies that the agenda influence of the Commission is likely to decrease as the status quo approaches the position of the Council members-and does not increase as conjectured by Tsebelis (p. 139). In addition, the effect of a progressive EP is much more limited than Tsebelis argues; in most cases the EP can only beg the Commission and the Council to reconsider.

Finally, the influence of a prointegrationist EP is not modified in the codecision procedure (Article 189b) because amendments by the EP are treated similarly in both procedures. Also in the codecision procedure, amendments have to be approved by a qualified majority of the Council if the Commission supports them, otherwise by unanimity. The major difference between these two procedures is that the EP can be outvoted by a unanimous Council in the cooperation procedure, while the EP has an absolute veto power in the codecision procedure. That is, if the Council does not approve the amendments and the Conciliation Committee fails to reach a compromise, then the Council can confirm the common position "to which it agreed before the conciliation procedure was initiated, possibly with amendments proposed by the European Parliament" [Article 189b(6), emphasis added]. The EP can only threaten to veto the whole legislation and thereby maintain the status quo, which is of limited value for a prointegrationist EP. ${ }^{4}$

\footnotetext{
${ }^{3}$ Of course, the EP can (and does) substantially delay a policy change already in the first reading because the Council can only approve a common position if the EP has given its opinion. There is no time limit for the EP to act, although it is doubtful whether the EP could openly block decision-taking in the conciliation procedure or in the first reading of the cooperation procedure (see Jacobs and Corbett 1990, $165)$.

${ }^{4}$ In one respect the influence of amendments by the EP may increase
}

\section{INTERPRETATION OF EMPIRICAL EVIDENCE}

Tsebelis' research is motivated by empirical evidence that amendments by the EP are surprisingly often accepted by the Commission and supported by the Council. Summarizing data from 1987 to 1991, Tsebelis concludes that "of every four EP amendments, two are accepted, one is rejected by the Commission, and one is rejected by the Council" (p. 136, emphasis added). Some of these amendments demanded major policy changes, as in the case of automobile emission standards. If the EP is so weak, as I argue, then why does it have such a profound effect on EU policy choices in some cases?

While I regard the explanation offered by Tsebelis as unconvincing, he deserves credit for addressing this important issue in a rigorous manner. There is a more persuasive way to explain the empirical evidence, however, based on accurately specified decision rules: Once the Council has adopted the common position, the Commission can no longer change its proposal (Article $189 \mathrm{a}[2])$ even if it wishes to do so. At this stage, only the EP can suggest amendments. Such proposals can be successful if restrictions have changed between the adoption of the common position in the Council and the final reading in the Council.

I can identify three kinds of potential changes in the restrictions that make a successful amendment by the EP feasible (see Moser forthcoming for a comprehensive discussion). First, consider a situation in which the decisive Council member is the binding restriction, that is, the Commission and the EP want more integration, but the Commission is constrained in its proposal at the first stage by the requirement to be supported by a qualified majority in the Council. Suppose that after the adoption of the common position in the first reading of the Council, the decisive member changes position toward more integration. Using Figure 1, this implies that the ideal point of member 3 moves to the right. Such a revision of a government's position can be due to a change of the party (or party coalition) in power or to altered public perception of an issue. Both the Commission and the EP would like to take advantage of this change, but only the EP can propose amendments to the common position after the first reading in the Council. Consequently, the EP makes an amendment which is supported by the Commission (and which the Commission could not make in the first stage) and by a qualified majority in the Council.

Second, consider a situation in which the Commission's ideal point is closer to the status quo than that of the decisive member in the Council. Hence, the Commission can realize a common position at its ideal point. If its preferences change (e.g., the responsible Commissioner is replaced), then any change in the Commission's

in the codecision procedure compared to the cooperation procedure. In the Conciliation Committee, the Council and the EP can agree on amendments that may be opposed by the Commission and approve them by qualified majority and absolute majority, respectively. Tsebelis (1995) comes to the different conclusion that the codecision procedure reduces the influence of the EP because he assumes that the Council is free to choose a policy if no agreement is reached in the Conciliation Committee. This assumption contradicts Article $189 \mathrm{~b}(6)$. 
position toward the ideal point of the EP can be exploited by the EP in its second reading. In Figure 1, suppose that the Commission's ideal point was at 2 and moves to 3. With the common position at 2, the EP can make a proposal to the right of 3 such that the Commission is marginally better off than with the common position at 2 and such that decisive Council member 3 supports it.

Third, perceptions of what might happen if the status quo prevails can change. Quite often in EU politics, member states that advocate a major policy change threaten to enact it unilaterally if no satisfactory decision is forthcoming in the EU. The possibilities for unilateral action by the member states are defined by the treaty. In addition, a decision by the European Court of Justice can modify the perceived possibility of unilateral actions. If such a decision occurs in the course of decision making, the reversion policy may change such that the Commission is prepared to adopt a previously unaccept- opposite direction from the Commission, however, then the veto rights of the EP would become effective. In this respect, the cooperation procedure grants the EP conditional veto rights, depending on particular preference configurations. Furthermore, if in the future the status quo approaches the position of the members in the Council, then the influence of the agenda setter is likely to decrease, not increase, as argued by Tsebelis.

Yet, the EP's amendment rights can shift EU decisions closer to the EP's prointegration position if the views of the key players change after the adoption of the common position. Examples are shifts in the position of the decisive Council member or of the Commission, or modifications in the reversion point. Whether such changes in the restrictions can explain the large number of successful amendments by the EP is an open empirical question that requires careful analysis of individual cases.

\footnotetext{
- . . . .
}

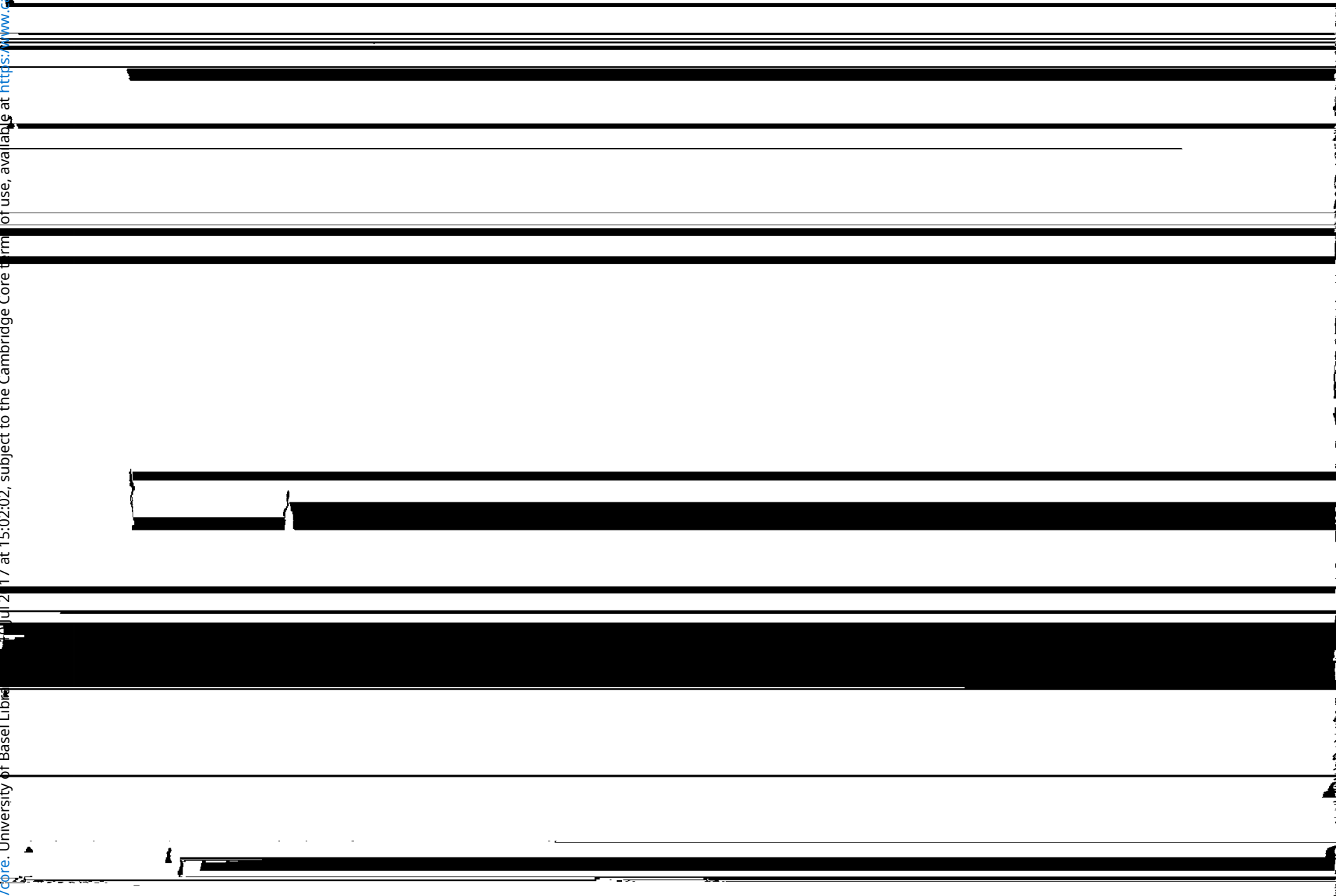

